\title{
La influencia de la iniciativa URBANA 2007-2013 en el desarrollo de la capacidad institucional de la administración municipal
}

\author{
The influence of the URBANA 2007-2013 Initiative on the \\ development of the Institutional Capacity of Local Administration
}

\author{
Valle Casado Maestre \\ Universidad Pablo de Olavide \\ v.casado.maestre@gmail.com
}

\section{NOTA BIOGRÁFICA}

Es titulada en Derecho por la Universidad de Córdoba, Máster en Sociedad, Administración y Política por la Universidad Pablo de Olavide de Sevilla. Actualmente colabora con el Departamento de Sociología de esta universidad investigando sobre política urbana europea y desarrollo de la capacidad institucional.

\section{María Ángeles Huete García Universidad Pablo de Olavide mahuegar@upo.es}

\section{NOTA BIOGRÁFICA}

Es profesora e investigadora del Departamento de Sociología de la Universidad Pablo de Olavide, de Sevilla. Responsable del Grupo de Investigación en Gobernanza Urbana y Metropolitana (GUM-Z) (Sej-606). Es doctora en Sociología (Mención Europea) por la Universidad Pablo de Olavide (2008). Su investigación se centra en el análisis de políticas públicas y gobernanza, con especial atención al ámbito urbano.

\section{Rafael Merinero Rodríguez Universidad Pablo de Olavide rmerrod@upo.es}

\section{NOTA BIOGRÁFICA}

Es profesor del Departamento de Sociología de la Universidad Pablo de Olvide de Sevilla donde imparte las asignaturas de Sociología Política y Análisis y Evaluación de Políticas Públicas. Es Doctor (con Mención Europea) por la Universidad de Sevilla y su línea de investigación se centra en el estudio de la gobernanza como marco fundamental para las políticas públicas.

\author{
Moneyba González Medina \\ Universidad Autónoma de Madrid \\ moneyba.gonzalez@uam.es
}

\section{NOTA BIOGRÁFICA}

Doctora en Ciencia Política y de la Administración (Mención Europea) por la Universidad de Santiago de Compostela (2009). Es profesora e investigadora del Departamento de Ciencia Política y Relaciones Internacionales de la Universidad Autónoma de Madrid. Su investigación se enmarca en el análisis de las políticas públicas y la modernización de las administraciones, con especial atención al ámbito urbano. 
GAPP. Nueva Época - N. 20, noviembre 2018 - ISSN: 1989-8991 - DOI: 10.24965/gapp.v0i20.10487 - [Págs. 124-142] Número monográfico - Gobernanza y políticas de desarrollo urbano: teoría y práctica

La influencia de la iniciativa URBANA 2007-2013 en el desarrollo de la capacidad institucional de la administración municipal Valle Casado Maestre / María Angeles Huete García / Rafael Merinero Rodríguez / Moneyba González Medina

\title{
RESUMEN
}

Desde hace años, la Unión Europea viene haciendo especial énfasis en la promoción de la capacidad institucional de las administraciones en el marco de los programas de desarrollo local y urbano. Sin embargo, hasta el momento son pocos los trabajos destinados al análisis de la capacidad institucional entre las administraciones locales españolas como producto de estas iniciativas. Este trabajo se destina al estudio de la promoción de dicha capacidad en las ciudades españolas que han implementado programas de desarrollo, en concreto, la iniciativa URBANA 2007-2013. A través de la administración de un cuestionario entre los ayuntamientos españoles y entrevistas en profundidad con actores clave en el diseño e implementación del programa, se trata de analizar la medida en que dicha capacidad se ha desarrollado, así como la relación entre su nivel de desarrollo y otros elementos del contexto local o institucional, como son la experiencia previa acumulada en programas similares y el modelo de gestión en el marco del cual se implementa el programa. Estos elementos se mostrarán como factores clave en el desarrollo de la capacidad institucional.

\section{PALABRAS CLAVE}

Desarrollo urbano; política urbana europea; capacidad de la administración; experiencia previa; modelo de gestión.

\begin{abstract}
For years, the European Union has placed special emphasis on the promotion of the institutional capacity of administrations that, through various financing instruments, promote local and urban development programs. So far there are few works aimed at the analysis of institutional capacity among Spanish local administrations as a result of these initiatives. This work is intended to study the promotion of this capacity in Spanish cities that have implemented urban development programs, more precisely, the URBAN 20072013 initiative. Through the administration of a questionnaire among Spanish municipalities, the aim is to analyse the extent to which the institutional capacity has been developed, as well as the relationship between its level of development and other elements of the local context, such as the previous experience accumulated in similar programs and the management model within which the program is implemented, elements that will be revealed key factors in the degree of development of institutional capacity.
\end{abstract}

\section{KEYWORDS}

Urban Development; European Urban Policy; Urbana Programme 2007-2013; Institutional Capacity Building; Management Model.

\section{SUMARIO}

0. INTRODUCCIÓN. 1. APROXIMACIÓN AL CONCEPTO DE CAPACIDAD INSTITUCIONAL Y SUS PRINCIPALES DIMENSIONES. 2. LA CAPACIDAD INSTITUCIONAL COMO PROCESO DE CAMBIO A PARTIR DEL APRENDIZAJE. 3. EL MODELO DE DESARROLLO URBANO EUROPEO COMO MARCO PARA EL APRENDIZAJE. 4. LA CAPACIDAD INSTITUCIONAL EN LOS PROGRAMAS EUROPEOS DE DESARROLLO URBANO. 5. FUENTES DE INFORMACIÓN UTILIZADAS. 6. PRINCIPALES RESULTADOS. 6.1. CAPACIDAD DE GESTIÓN: IMPLEMENTACIÓN DEL PROGRAMA. 6.2. CAPACIDAD PARA LA GESTIÓN DE LAS ALIANZAS. 6.3. CAPACIDAD PARA APLICAR EL ENFOQUE INTEGRADO. 7. CONCLUSIONES. DOCUMENTOS.

\section{INTRODUCCIÓN}

La cuestión de la capacidad institucional cobra especial importancia en el contexto de la gobernanza y de las políticas promovidas por la Unión Europea. Los recursos destinados específicamente a este aspecto en los Fondos Estructurales $1^{1}$ (EU, 2014) así lo evidencian. Junto a ello, diversos estudios señalan que la

1 El Objetivo 11 se denomina Mejorar la capacidad institucional de las autoridades públicas y las partes interesadas y la eficiencia de la administración pública. Ver el artículo 9 del Reglamento (UE) núm. 1303/2013 del Parlamento Europeo y del Consejo, de 17 de diciembre de 2013, por el que se establecen disposiciones comunes a los Fondos Europeos. 
capacidad institucional es un factor clave para la gobernanza territorial (Böhme et al., 2015). Por esta razón, la Unión Europea, desde hace años, viene haciendo especial énfasis en la promoción de la capacidad institucional de las administraciones en los programas de desarrollo local y urbano.

Existe un reconocimiento explícito por parte de las instituciones europeas sobre el impacto que los fondos europeos producen en el desarrollo de la capacidad institucional de las administraciones que los gestionan. Así, la Comisión Europea (2015) señala que, «apoyar la capacidad administrativa es poner en marcha las estructuras, los recursos humanos, los sistemas y las herramientas adecuados. En otras palabras, garantizar que las responsabilidades y las tareas estén claramente asignadas; el personal correctamente entrenado; y que se contrate a las personas adecuadas para gestionar los fondos. (...) Otro elemento importante es la gobernanza, que supone exigir responsabilidades sobre el rendimiento a los gestores, prevenir la corrupción y el conflicto de intereses, así como fomentar la transparencia».

Busetti y Pacchi (2015:16) señalan que en los «debates previos al periodo de programación 2014-2020 [...] se insiste en la importancia creciente de la capacidad institucional entendida como la habilidad de las administraciones públicas para proporcionar políticas eficaces, gracias a las mejoras en su diseño, implementación y evaluación».

Con el propósito de profundizar en esta cuestión, este trabajo tiene como objetivo analizar el desarrollo de la capacidad institucional en municipios que han implementado iniciativas europeas de carácter urbano, tomando como objeto de análisis la iniciativa URBANA, impulsada por España en el marco de la programación del Fondo Europeo de Desarrollo Regional (FEDER) durante el periodo 2007-2013.

La hipótesis de partida es que la implementación de programas europeos de carácter urbano produce cambios en la capacidad institucional de los municipios que los implementan, y que esos cambios les permiten afrontar en mejores condiciones los retos y problemáticas que viven las ciudades de hoy en día. Ahora bien, dicha capacidad no se desarrollará en la misma medida ni de la misma forma en las diferentes administraciones. En ello jugarán un papel importante elementos del contexto local o institucional, como la experiencia previa en la gestión de programas similares, y el modelo de gestión en el marco del cual se sustenta la implementación de la iniciativa. Por un lado, la experiencia previa de una administración local puede implicar un desarrollo de la capacidad institucional de partida que tendrá que ser tenido en cuenta como elemento diferenciador de los resultados obtenidos; por otro, se considera que el modelo de gestión en el que se ubica el programa constituye un elemento fundamental para la adquisición de la capacidad institucional y, que de aquellos programas implementados por oficinas ad hoc, derivarán en mayores aprendizajes. Este trabajo pondrá en relación ambos elementos con las dimensiones que desarrollaremos más adelante, con el objeto de analizar el grado de desarrollo de la capacidad institucional en las administraciones objeto de este estudio.

Para ello, el artículo se estructura de la siguiente forma. La primera parte ofrece un marco conceptual en torno a las teorías que explican la capacidad institucional y sus procesos de cambio a través del aprendizaje en el seno de la administración. A continuación, se reflexiona sobre cómo los programas europeos de carácter urbano suponen un cambio en la capacidad institucional de las administraciones que los implementan. Se definirán con posterioridad las dimensiones principales que van a permitir operacionalizar el objeto de estudio y, para terminar, se expondrán los principales resultados de la investigación y se adelantarán algunas conclusiones.

\section{APROXIMACIÓN AL CONCEPTO DE CAPACIDAD INSTITUCIONAL Y SUS PRINCIPALES DIMENSIONES}

Respecto a la construcción de la capacidad en el sector público, Hilderbrand y Grindle (1997:34) sostienen que la «capacidad es la habilidad para desempeñar tareas de una manera efectiva, eficiente y sostenible». Yendo un paso más allá, Rosas (2008) considera que la capacidad institucional puede entenderse como solvencia para mejorar las funciones, resolver problemas, movilizar o adaptar las instituciones para dar respuesta a los problemas públicos. En definitiva, el concepto de capacidad institucional podría entenderse como suficiencia de la administración para responder a los retos clásicos que se le vienen planteando desde hace años, esto es, una gestión basada en la eficacia, la eficiencia, con capacidad para establecer alianzas con otros actores, tanto en el seno de la administración local como fuera de ella.

A este respecto, si entendemos como dimensiones de la capacidad institucional la eficiencia, la eficacia, la capacidad relacional y la transparencia, diferentes aportaciones en la literatura han puesto el foco en una u otra de estas dimensiones fundamentales. Así, en relación con la capacidad como eficacia, Sikkink (1993) 
GAPP. Nueva Época - N. 20, noviembre 2018 - ISSN: 1989-8991 - DOI: 10.24965/gapp.v0i20.10487 - [Págs. 124-142] Número monográfico - Gobernanza y políticas de desarrollo urbano: teoría y práctica

La influencia de la iniciativa URBANA $2007-2013$ en el desarrollo de la capacidad institucional de la administración municipal Valle Casado Maestre / María Angeles Huete García / Rafael Merinero Rodríguez / Moneyba González Medina

pone el acento en la eficacia administrativa, entendida como la habilidad para mejorar las funciones, resolver problemas y especificar objetivos.

La capacidad como eficiencia, o logro de objetivos con los medios adecuados, es abordada, entre otros, por Repetto (2003), quien hace referencia a las aptitudes de las instancias gubernamentales para plasmar en sus políticas públicas los más altos niveles posibles de valor social. Este autor pone énfasis en la capacidad de gestión pública, haciendo alusión a quién se encarga de hacer las políticas, con qué medios cuentan para hacerlo y bajo qué reglas institucionales operan. Por su parte, Savitch (1998) hace referencia a la habilidad de las organizaciones para absorber responsabilidades, operar más eficientemente y favorecer la rendición de cuentas.

Junto a ellos, la literatura es muy prolífica en la capacidad institucional de las administraciones locales para trabajar de forma colaborativa. Así, Healey (1998) centra su análisis en la capacidad institucional orientada a fortalecer la capacidad de los decisores locales para incrementar su poder y diferenciar las cualidades de sus territorios. Esta capacidad institucional combina tres dimensiones: el capital intelectual o recursos cognitivos, el capital social o recursos relacionales y el capital político o capacidad de movilización.

En esta misma línea, para Rosas (2008:129), «la capacidad institucional depende no sólo de la existencia de organizaciones administrativas coherentes y cuadros burocráticos expertos bien motivados (capacidad administrativa), sino también de la constitución y acción de los actores sociopolíticos involucrados en un determinado campo de acción pública» (capacidad relacional).

En definitiva, podría afirmarse que la capacidad institucional hace referencia a la habilidad de las administraciones para resolver problemas (eficacia), utilizando adecuadamente los recursos a su disposición (eficiencia) y estableciendo relaciones de colaboración con los actores del contexto en el que operan (relacional).

\section{LA CAPACIDAD INSTITUCIONAL COMO PROCESO DE CAMBIO A PARTIR DEL APRENDIZAJE}

La adquisición o desarrollo de la capacidad institucional implica un proceso de cambio en la forma en que se formulan, gestionan, y evalúan las políticas. Dicho proceso de cambio se produce como efecto de lo que podríamos denominar aprendizaje, entendido éste como la acumulación de destrezas y habilidades a lo largo del proceso de generación e implementación de una política pública. El proceso de aprendizaje será más intenso cuanto más elevado sea el nivel de exigencia técnica que requiere el diseño y la implementación de una política.

En este sentido y para enmarcar el aprendizaje como proceso para el desarrollo de la capacidad institucional en el contexto de programas urbanos financiados con fondos comunitarios, conviene traer a colación a Real Dato (2007), quien establece una explicación de los cambios en torno a tres procesos causales generativos o mecanismos de cambio, a saber: expansión del conflicto, procesos exógenos y elementos endógenos.

Los cambios por expansión del conflicto se producen como efecto de un proceso de movilización de determinados actores que, no conformes con su funcionamiento, tratan de subvertir el contenido de una política.

Por su parte, los cambios como resultado de procesos exógenos se relacionan más bien con acontecimientos críticos (crisis políticas o económicas, catástrofes), cambios constitucionales, transformaciones en la opinión pública o en la cultura política, relevo de gobierno, reorganizaciones administrativas, cambios en otros subsistemas vinculados o en subsistemas homólogos o similares (spill overs), etc.

Finalmente, las transformaciones en las políticas como efecto de factores endógenos, se producirían como resultado del procesamiento de información, lo que implica una serie de pasos intermedios: adquisición, distribución, interpretación y almacenaje de conocimiento (Huber, 1991). En este caso, el cambio puede producirse a partir de recetas previamente establecidas, o a través de un proceso de aprendizaje, que puede ser, a su vez, un «aprendizaje político» ${ }^{2}$ y un «aprendizaje sobre políticas» ${ }^{3}$.

La información procesada, según Real Dato (2007) puede generarse a partir de diferentes fuentes: una fundamental son los resultados producidos a lo largo del tiempo por el diseño de una política; otra tiene su origen en las condiciones externas que afectan a la efectividad de la política; por último, la información relevante puede proceder de otras arenas de acción con las que pueda estar relacionada.

\footnotetext{
2 Según May (1992): se refiere al aprendizaje por el cual los actores políticos adquieren un mayor grado de sofisticación en la persecución y promoción de sus intereses.

3 Hace referencia, según el mismo autor, al aprendizaje orientado hacia una mejor comprensión, e incluso, redefinición de los objetivos, metas, instrumentos, justificaciones y demás componentes del diseño de una política pública.
} 
Real Dato (2007:14) señala que la producción de conocimiento es, en primer lugar, un proceso individual y que el aprendizaje tiene lugar cuando el conocimiento individual es incorporado y codificado dentro de las rutinas colectivas y prácticas $\mathrm{o}$, en otras palabras, queda institucionalizado dentro de la entidad colectiva.

En este sentido, y respecto a los programas europeos como mecanismo de aprendizaje, es importante señalar que si por algo se caracterizan estos programas, es por plantear una serie de directrices, tanto en su contenido como en los procedimientos de gestión, cuya puesta en práctica supone en buena medida una condición indispensable para el acceso de los recursos económicos que financian estas iniciativas. Así, es de suponer que en el marco de estas actuaciones se produciría, en primer lugar, una adaptación por parte de las administraciones locales a aspectos tales como los requerimientos técnicos en su diseño e implementación (p. ej. la utilización de determinadas herramientas de diagnóstico, como una matriz DAFO), pero también establecimiento de procesos de colaboración con otras áreas municipales o con la ciudadanía (p. ej. la realización de un proceso de participación ciudadana) y, finalmente, procedimientos concretos para garantizar la transparencia en el uso de los fondos (p. ej. la utilización de indicadores de proceso y de resultado asociados a las actuaciones). Dichos ajustes, en un primer momento, podrían darse como consecuencia de la búsqueda de recursos económicos que suponen los fondos europeos. En esta línea, autores como Healey (1998) vienen señalando que la alineación por parte de los estados miembros al modelo que se desprende de los programas europeos, a veces no se debe tanto a una modificación en la cultura política y administrativa de las administraciones locales, sino más bien a la obligatoriedad que conlleva la aplicación de los fondos, en un contexto de competición por los recursos a disposición de las ciudades.

Sin embargo, el proceso de aprendizaje generado en torno a estos programas se iría incorporando finalmente a las rutinas colectivas dentro de la administración, más allá de la, en ocasiones, motivación inicial de búsqueda de financiación; pasando de un carácter individual (en relación con las rutinas de los empleados municipales) a colectivo, para finalmente quedar institucionalizado en el conjunto de la administración más allá del periodo de implementación de los fondos, y más allá de la unidad que implementa el programa; tanto en las políticas de características similares y financiadas con fondos europeos como en el conjunto de políticas de la ciudad.

En definitiva, se asume que la implementación del programa URBANA por las administraciones locales, lleva aparejado un proceso de aprendizaje y, como consecuencia, la adquisición por parte de los responsables políticos y técnicos, de una serie de habilidades y conocimientos que puede suponer un desarrollo de la capacidad institucional de los mismos. Ahora bien, dicho aprendizaje y, sobre todo, la capacidad institucional alcanzada a lo largo de la implementación del programa no se producirá de la misma forma en todos los municipios, sino que en ello jugarán un papel relevante elementos como la experiencia previa o el modelo de gestión en el que se inserta el programa.

FIGURA 1. EL CAMBIO EN UNA POLÍTICA PÚBLICA COMO RESULTADO DEL APRENDIZAJE

\begin{tabular}{|c|c|c|c|}
\hline $\begin{array}{l}\text { Contexto local } \\
\text { Experiencia } \\
\text { previa. } \\
\text { Modelo de } \\
\text { gestión. }\end{array}$ & $\begin{array}{l}\qquad \begin{array}{l}\text { Marco } \\
\text { normativo }\end{array} \\
\text { Reglas que } \\
\text { regulan el } \\
\text { programa } \\
\text { URBANA }\end{array}$ & \begin{tabular}{l}
\multicolumn{1}{c}{ Actores } \\
Adquisición de \\
conocimiento por \\
parte de los \\
técnicos/políticos \\
municipales
\end{tabular} & $\begin{array}{l}\text { Incrementos en } \\
\text { la capacidad } \\
\text { institucional } \\
\text { Modificaciones } \\
\text { en el diseño y la } \\
\text { gestión de las } \\
\text { políticas urbanas } \\
\text { en las } \\
\text { administraciones } \\
\text { locales. }\end{array}$ \\
\hline
\end{tabular}

Fuente: Elaboración propia.

En este punto resulta relevante profundizar en los elementos que configuran el modelo de desarrollo integrado del programa URBANA, a partir de las cuales se van a estudiar los procesos de cambio en las administraciones que los implementan. 


\section{EL MODELO DE DESARROLLO URBANO EUROPEO COMO MARCO PARA EL APRENDIZAJE}

Es destacable que, aunque la UE no tiene competencias formales en materia de desarrollo urbano, desde la década de los ochenta es muy significativa la creciente producción de documentos de orientación política que han favorecido la visibilidad de las ciudades en la arena política comunitaria. Todo ello, si bien no es suficiente para constituir una política urbana de carácter formal, ha supuesto sin ningún género de dudas un marco a partir del cual establecer un esquema común de política urbana europea en la práctica. Este marco se plasma en diversos programas entre los que destacan los orientados específicamente a las ciudades como los Proyectos Piloto Urbanos en su fase I (1989-1994) y fase II (1997-1999); las iniciativas comunitarias URBAN I (1994-1999) y URBAN II (2000-2006) o los programas URBANA y PIDLU, impulsados en España durante el periodo 2007-2013, cuyo enfoque se mantiene en el actual periodo 2014-2020 a través de las Estrategias de Desarrollo Urbano Sostenible e Integrado (EDUSI). Por su parte, el programa URBACT nace en 2002 como una red de intercambio de conocimiento y de buenas prácticas así como de capacitación institucional en materia de desarrollo urbano. En el actual periodo de programación 2014-2020, URBACT ha aumentado su presupuesto.

Además del conjunto de documentos políticos y de instrumentos de política pública surgidos desde el ámbito europeo, se puede inferir que el modelo de desarrollo urbano que subyace a todos ellos se sustenta sobre la base de dos dimensiones fundamentales. Una, relacionada con el contenido de las iniciativas, o lo que podríamos denominar su dimensión sustantiva. Otra, atiende a la forma en que se aborda la gestión de los programas, tanto en el seno de la administración como en relación a actores ajenos a ella, o lo que podríamos denominar su dimensión procedimental.

De forma concreta, respecto a la dimensión sustantiva, el modelo de desarrollo urbano europeo se sustenta sobre la base de un enfoque sostenible e integrado, que tiene que ver con tratar la definición y la solución de los problemas teniendo en cuenta de forma conjunta todas sus dimensiones: económicas, culturales, sociales, medioambientales y físicas. Ello supone disponer, en primer lugar, de una visión de conjunto de las cuestiones urbanas sobre las que se pretende intervenir y, después, adoptar una perspectiva integral para identificar y llevar a cabo las soluciones.

Respecto a la dimensión procedimental, referida a aspectos relacionados con la gestión, el modelo de desarrollo urbano hace referencia al proceso de integración de otros actores o, dicho de otro modo, a la capacidad de colaboración y cooperación de los diferentes actores públicos y privados que puedan estar afectados por los problemas o por sus previsibles soluciones, para su delimitación y caracterización, la elaboración de programas y la implementación de las actuaciones. Esta gestión de redes de actores implica la denominada coordinación horizontal (o de las diferentes áreas de gobierno), la cooperación vertical (o multinivel entre diferentes tipos y niveles de gobierno) y la colaboración con agentes de la sociedad local (empresas o grupos organizados sin ánimo de lucro, así como ciudadanos individualmente).

Finalmente, respecto a la gestión de cara al interior de la administración, (González, 2011:53) encuentra en los ejes de la estrategia urbana europea recomendaciones a las ciudades para que pongan en marcha procesos de planificación integrados, que deberán incorporar la elaboración de diagnósticos, así como definir los objetivos que conformarán la estrategia de la ciudad, la coordinación con otros planes sectoriales y el aprovechamiento de los fondos a los que acceden. En el marco de los instrumentos concretos, los programas, se establecerá claramente una serie de requerimientos de carácter técnico, destinados al logro de una gestión más eficaz y eficiente.

Toda esta experiencia generada en torno al cada vez más consolidado modelo de desarrollo urbano europeo que los ámbitos locales han ido adquiriendo en el transcurso de la implementación de iniciativas europeas, va conformando lo que se viene a llamar el acervo urbano o, lo que es lo mismo, una metodología europea común de intervención, un cuerpo de conocimiento y buenas prácticas ${ }^{4}$ en materia urbana (Atkinson y Rossignolo, 2009:2).

Diversas aportaciones (De Gregorio, 2010; De Gregorio, 2014; Huete et al., 2016) han indagado en los resultados de la implementación de algunos programas europeos de desarrollo urbano, tales como URBAN

4 Traducción del original: «(...) the term acquis urbain is increasingly being used to suggest the building up a common European methodology of intervention, a body of knowledge and examples of action that can be seen in broadly similar terms to the acquis communitaire». 
GAPP. Nueva Época - N. 20, noviembre 2018 - ISSN: 1989-8991 - DOI: 10.24965/gapp.v0i20.10487 - [Págs. 124-142] Número monográfico - Gobernanza y políticas de desarrollo urbano: teoría y práctica

La influencia de la iniciativa URBANA 2007-2013 en el desarrollo de la capacidad institucional de la administración municipal Valle Casado Maestre / María Angeles Huete García / Rafael Merinero Rodríguez / Moneyba González Medina

I, URBAN II o URBANA. Si bien en ninguno de los casos se concluye que este proceso se genera de manera completamente satisfactoria, podría asumirse una cierta adaptación al modelo de desarrollo urbano europeo como consecuencia de la implementación de estos programas o, más bien, como efecto de la aplicación de lo que viene conociéndose como «enfoque urbano europeo», es decir, los principios y metodologías de gestión que conlleva la ejecución de los fondos a los que concurren las ciudades. Como consecuencia de este proceso, se están produciendo dinámicas de «Europeización» ${ }^{5}$ en las Administraciones locales.

Ahora bien, los efectos que los procesos de desarrollo de la capacidad institucional derivados de la práctica del acervo urbano europeo están produciendo en las ciudades no han sido analizados hasta la fecha. Este trabajo viene a iniciar este análisis a partir de la iniciativa URBANA del periodo 2007-2013.

El siguiente apartado aborda el tratamiento analítico del concepto de capacidad institucional y su análisis desde la perspectiva del modelo de desarrollo urbano integrado.

\section{LA CAPACIDAD INSTITUCIONAL EN LOS PROGRAMAS EUROPEOS DE DESARROLLO URBANO}

Tal como se ha señalado al inicio del trabajo, la capacidad institucional hace referencia a la habilidad de las administraciones para acometer sus tareas de una forma eficaz, eficiente y colaborativa. En este sentido, a tenor de las dimensiones que sustentan el modelo de desarrollo urbano europeo, parece lógico pensar que los programas europeos de carácter urbano constituyen un ámbito de análisis idóneo para la promoción de aprendizajes derivados de enfoques y formas de hacer que las administraciones locales han de poner en marcha al objeto de poder concurrir a los fondos con los que se financian estos programas.

Tal como se muestra en la Tabla 1, las dimensiones de la capacidad institucional definidas de forma genérica en la literatura bien podrían constituir equivalentes funcionales o proxis de los elementos que conforman en el modelo de desarrollo urbano europeo. Así, el enfoque integrado trata de lograr una mejor respuesta a la realidad urbana, atendiendo a sus diferentes dimensiones. Junto a ello, la gestión innovadora de los programas, redundaría no solamente en la capacidad para el logro de una gestión eficaz, sino también eficiente, o la búsqueda de una forma más racional de ejecutar y justificar los fondos.

Finalmente, el enfoque colaborativo de la capacidad institucional se vería claramente reflejado en la habilidad de la administración para establecer alianzas con actores que de una forma u otra tienen una implicación con la política. Ya sea en el interior o en el exterior de la administración; cuestión a la que el modelo de desarrollo urbano presta especial atención y constituye uno de sus elementos fundamentales.

Así, se plantea la medición y estudio de la capacidad institucional de los municipios a partir de tres dimensiones concretas, que se ha entendido constituyen las características definitorias de estos programas europeos y que son coherentes con las dimensiones que plantea la literatura sobre la capacidad institucional, a saber: modelos de gestión innovadores, enfoque colaborativo y carácter integrado.

TABLA 1. DIMENSIONES DE LA CAPACIDAD INSTITUCIONAL Y DEL DESARROLLO URBANO EUROPEO

\begin{tabular}{lccc}
\hline \multicolumn{1}{c}{ Modelo desarrollo urbano europeo } & Capacidad institucional & & \\
\hline Dimensiones & Eficacia & Eficiencia & Enfoque relacional \\
\hline Modelos de gestión innovadores & $X$ & $X$ & $X$ \\
\hline Enfoque colaborativo & & & \\
\hline Carácter integrado & $X$ & & \\
\hline
\end{tabular}

Si bien la capacidad institucional se analiza en relación con las tres dimensiones expuestas, este trabajo parte de la idea de que esta capacidad se desarrolla de forma diferente en función de algunos elementos

${ }^{5}$ La Europeización ha sido definida como un proceso de (a) construcción, (b) difusión y (c) institucionalización de normas formales e informales, paradigmas de políticas públicas, estilos y «formas de hacer», así como creencias compartidas y reglas que son incialmente definidas y consolidadas en la formación de políticas en la UE, y, en consecuencia, incorporadas en el el nivel nacional en la lógica del discurso, identidades, estructuras y políticas públicas (Radaelli, 2003: 30). 
GAPP. Nueva Época - N. ${ }^{\circ}$ 20, noviembre 2018 - ISSN: 1989-8991 - DOI: 10.24965/gapp.v0i20.10487 - [Págs. 124-142] Número monográfico - Gobernanza y políticas de desarrollo urbano: teoría y práctica

La influencia de la iniciativa URBANA $2007-2013$ en el desarrollo de la capacidad institucional de la administración municipal Valle Casado Maestre / María Angeles Huete García / Rafael Merinero Rodríguez / Moneyba González Medina

como la experiencia previa en la implementación de programas similares, o el modelo de gestión en el que se inserta la implementación del programa.

En relación a la experiencia previa, y como dijimos más arriba, se parte de la hipótesis de que no todos los casos experimentarán el mismo proceso de aprendizaje. En ello jugará un papel clave la inercia creada como producto de la gestión de programas similares. Así, la experiencia previa de una administración local puede implicar un desarrollo de la capacidad institucional de partida que ha de ser tenida en cuenta como elemento diferenciador de los resultados obtenidos. En el marco de este trabajo, se ha considerado no solamente la experiencia en programas similares financiados con fondos europeos, sino también otros programas de desarrollo urbano, implementados en el municipio o área objeto de actuación.

En este sentido, (Parés et al., 2014) ya se ha puesto de manifiesto que la experiencia acumulada con la implementación de programas anteriores crea una inercia que favorece una forma diferente de gestionar los programas, por ejemplo, en lo que a participación ciudadana se refiere.

Asimismo, el tipo de estructura de gestión del que la administración local se dota constituye otro elemento fundamental que podría introducir diferencias tanto en los impactos que puedan derivarse del aprendizaje que se obtenga de la implementación de los programas, como en la manera en la que estos impactos van a permanecer en la administración una vez que el programa concluya. De esta forma, el modelo de gestión interna constituye un elemento fundamental en relación con la adquisición de capacidad institucional de las administraciones. Se distingue entre modelos de gestión ubicados en una sola área municipal que gestiona el programa; sustentados sobre varias áreas que lo gestionan de forma conjunta; o bien la constitución de una oficina creada expresamente para la implementación del programa.

En este sentido, trabajos anteriores han puesto de manifiesto una mayor permeabilidad a la innovación en aquellas administraciones que han optado por una unidad de gestión creada al efecto (González y Merinero, 2013). Por ello, en relación a este elemento, la hipótesis es que aquellos programas implementados por oficinas ad hoc, en ocasiones al margen de la administración local, mostrarán mayores aprendizajes y, por ello, un mayor nivel de desarrollo de la capacidad institucional que los que se gestionan a partir de otros modelos de gestión localizados en la propia administración. Esta hipótesis parte de la convicción de que una estructura creada al efecto se adapta mejor a las propuestas del modelo gestión del desarrollo urbano europeo que las tradicionales estructuras de gestión.

Finalmente, al objeto de reconocer la medida en que la capacidad institucional se implanta en la administración, este trabajo considera que la capacidad institucional adquirida o desarrollada como efecto del aprendizaje tras la implementación de los programas europeos puede tener impactos más allá del área encargada de la implementación de estos programas (Real, 2007). Por ello, el análisis de la capacidad institucional se realiza en tres niveles o ámbitos de análisis, a saber: en el área o áreas encargadas de la implementación del programa europeo; en áreas objeto de implementación de otras políticas urbanas no financiadas con fondos europeos y, finalmente, en el conjunto de la administración.

Por tanto, este trabajo no solamente trata de conocer la naturaleza de la capacidad institucional a través del estudio de sus dimensiones (modelo de gestión innovador, enfoque integrado y colaborativo), sino también la extensión de la misma en la administración local que la implementa.

Teniendo en cuenta las conexiones existentes entre las dimensiones de la capacidad institucional y las presentes en el modelo de desarrollo urbano europeo, se muestra en el siguiente cuadro la propuesta de operacionalización de los conceptos en el marco de este trabajo.

TABLA 2. CAPACIDAD INSTITUCIONAL: OPERACIONALIZACIÓN DE CONCEPTOS

\begin{tabular}{|c|c|c|c|}
\hline Concepto & Dimensión & Indicador & Indice \\
\hline \multirow[t]{2}{*}{$\begin{array}{l}\text { Capacidad } \\
\text { institucional } \\
\text { (naturaleza) }\end{array}$} & \multirow[t]{2}{*}{$\begin{array}{l}\text { Capacidad de } \\
\text { gestión (interna) }\end{array}$} & $\begin{array}{l}\text { Organización del proceso de implementación del } \\
\text { programa URBANA. }\end{array}$ & \multirow[t]{2}{*}{$\begin{array}{l}\text { Valoración en } \\
\text { relación con la } \\
\text { importancia en la } \\
\text { implementación } \\
\text { del programa } \\
\text { URBANA. } \\
\text { Escala 0_5. }\end{array}$} \\
\hline & & Requerimientos técnicos del programa (checklist). & \\
\hline
\end{tabular}


GAPP. Nueva Época - N. ${ }^{\circ}$ 20, noviembre 2018 - ISSN: 1989-8991 - DOI: 10.24965/gapp.v0i20.10487 - [Págs. 124-142] Número monográfico - Gobernanza y políticas de desarrollo urbano: teoría y práctica

La influencia de la iniciativa URBANA 2007-2013 en el desarrollo de la capacidad institucional de la administración municipal Valle Casado Maestre / María Angeles Huete García / Rafael Merinero Rodríguez / Moneyba González Medina

\begin{tabular}{|c|c|c|c|}
\hline Concepto & Dimensión & Indicador & Indice \\
\hline & & $\begin{array}{l}\text { Distribución de las funciones durante el proceso de } \\
\text { implementación del programa. }\end{array}$ & \\
\hline & & $\begin{array}{l}\text { Innovaciones en la manera de gestionar distintos } \\
\text { aspectos del gobierno municipal. }\end{array}$ & \\
\hline & & Entre las distintas áreas del Ayuntamiento. & \\
\hline & Capacidad para & $\begin{array}{l}\text { Con otras administraciones (ayuntamientos, } \\
\text { gobierno regional, central, etc.). }\end{array}$ & \\
\hline & alianzas & $\begin{array}{l}\text { Con los actores de la sociedad (asociaciones } \\
\text { sociales, deportivas, vecinales, empresariales, de } \\
\text { barrios, empresas, cooperativas, ciudadanía no } \\
\text { organizada, etc.). }\end{array}$ & \\
\hline & Capacidad para & $\begin{array}{l}\text { EI DIAGNÓSTICO del programa se realizó teniendo } \\
\text { en cuenta las diferentes dimensiones de la realidad } \\
\text { de la zona objeto de actuación (física, económica, } \\
\text { social, ambiental, cultural, etc.). }\end{array}$ & \\
\hline & $\begin{array}{l}\text { aplicar el enfoque } \\
\text { integrado }\end{array}$ & $\begin{array}{l}\text { EI DISEÑO de las actuaciones del programa } \\
\text { se realizó teniendo en cuenta las diferentes } \\
\text { dimensiones de la realidad de la zona objeto de } \\
\text { actuación (física, económica, social, ambiental, } \\
\text { cultural, etc.). }\end{array}$ & \\
\hline \multirow{3}{*}{$\begin{array}{l}\text { Capacidad } \\
\text { institucional } \\
\text { (alcance) }\end{array}$} & Micro & $\begin{array}{l}\text { Impactos en el área/s u oficina que implementa el } \\
\text { programa URBANA. }\end{array}$ & \multirow{3}{*}{$\begin{array}{l}\text { Valoración del } \\
\text { impacto en } \\
\text { términos de } \\
\text { mejora a partir de } \\
\text { la implementación } \\
\text { del programa } \\
\text { URBANA. } \\
\text { Escala 0_5 }\end{array}$} \\
\hline & Meso & $\begin{array}{l}\text { Impactos en otras áreas no implicadas en el } \\
\text { programa que gestionan políticas de desarrollo } \\
\text { urbano. }\end{array}$ & \\
\hline & Macro & Impactos en el conjunto de la administración. & \\
\hline
\end{tabular}

Fuente: Elaboración propia.

\section{FUENTES DE INFORMACIÓN UTILIZADAS}

La metodología implementada para la obtención de información, ha sido tanto de carácter cuantitativo como cualitativo.

Por una parte, para llevar a cabo la obtención de la información necesaria, se ha administrado un cuestionario entre los 46 municipios que obtuvieron financiación en la convocatoria URBANA 2007-2013. Dicha actuación, dotada con 344 millones de euros de ayuda FEDER, estaba destinada a municipios con una población de derecho de más de 50.000 habitantes y capitales de provincia que no alcancen dicha cifra de población. En relación a los cuestionarios que se administraron a los 46 municipios que obtuvieron financiación del programa URBANA 2007-2013, se distribuyeron en formato online a través de la herramienta «formularios de Google», y estaban divididos en distintas categorías: Información general del municipio; Perfil de la ciudad: dos preguntas; Programa Urbana: siete preguntas; Participación del encuestado en la implementación de programas urbanos: dos preguntas; Programa EDUSI: siete preguntas.

Con el objetivo de completar la información cuantitativa obtenida a través de las preguntas cerradas, se permitía, en aquellas preguntas donde se consideró relevante, completar la información con opciones abiertas.

La muestra obtenida ha sido de 26 municipios, tal como se refleja en la ficha técnica de la Tabla 3. 
GAPP. Nueva Época - N. ${ }^{\circ}$ 20, noviembre 2018 - ISSN: 1989-8991 - DOI: 10.24965/gapp.v0i20.10487 - [Págs. 124-142] Número monográfico - Gobernanza y políticas de desarrollo urbano: teoría y práctica

La influencia de la iniciativa URBANA 2007-2013 en el desarrollo de la capacidad institucional de la administración municipal Valle Casado Maestre / María Angeles Huete García / Rafael Merinero Rodríguez / Moneyba González Medina

TABLA 3. FICHA TÉCNICA DEL CUESTIONARIO

\begin{tabular}{lc}
\hline $\begin{array}{l}\text { Universo: municipios que han desarrollado iniciativas de } \\
\text { regeneración URBANA en la convocatoria 2007/2013. }\end{array}$ & 46 \\
\hline Muestra: Municipios que han respondido al cuestionario. & 26 \\
\hline Tasa de respuesta. & 56,52 \\
\hline Información sobre el trabajo de campo. & $\begin{array}{r}\text { Encuesta administrada por internet entre técnicos } \\
\text { implicados en la implementación del programa. }\end{array}$ \\
\hline & Abril a junio de 2017. \\
\hline
\end{tabular}

Fuente: Elaboración propia.

Junto a ello, se realizaron tres entrevistas en profundidad con técnicos responsables de estos programas en el Ministerio de Hacienda, concretamente la Dirección General de Fondos Europeos, unidad de gestión dentro del gobierno de España encargada de la financiación, evaluación y seguimiento de estos programas (Tabla 4). Se consideró que el discurso de estos técnicos podría ser analíticamente relevante por poseer una visión del programa en su conjunto, dada su vinculación con el mismo para todos los municipios participantes en el programa, no solamente en el diseño de la convocatoria de ayudas, sino también en relación con el seguimiento de su implementación, la justificación de los fondos y su evaluación final.

TABLA 4. FICHA TÉCNICA DE LAS ENTREVISTAS EN PROFUNDIDAD

\begin{tabular}{lcclc}
\hline \multicolumn{1}{c}{ Nombre } & Código & Cargo & \multicolumn{1}{c}{ Organización } & Fecha \\
\hline $\begin{array}{l}\text { Anselmo Rodríguez } \\
\text { Bengoechea }\end{array}$ & ES1N & $\begin{array}{c}\text { DG Fondos } \\
\text { Europeos }\end{array}$ & $\begin{array}{l}\text { Ministerio de Hacienda y } \\
\text { Administraciones Públicas }\end{array}$ & $11-05-2017$ \\
\hline Dolores Ortiz Sánchez & ES2N & $\begin{array}{c}\text { DG Fondos } \\
\text { Europeos }\end{array}$ & $\begin{array}{l}\text { Ministerio de Hacienda y } \\
\text { Administraciones Públicas }\end{array}$ & $11-05-2017$ \\
\hline Emilia Martínez Urrutia & ES3N & $\begin{array}{l}\text { DG Fondos } \\
\text { Europeos }\end{array}$ & $\begin{array}{l}\text { Ministerio de Hacienda y } \\
\text { Administraciones Públicas }\end{array}$ & $11-05-2017$ \\
\hline
\end{tabular}

Fuente: Elaboración propia.

\section{PRINCIPALES RESULTADOS}

A continuación, se muestran los principales resultados obtenidos del análisis de los cuestionarios y las entrevistas en profundidad. Dichas evidencias se estructuran de acuerdo con la operacionalización mostrada más arriba. Por ello, se analiza en primer lugar cada uno de los elementos que componen la capacidad institucional, para después cruzarlos con la experiencia previa y el modelo de gestión.

Con el objetivo de conocer el efecto que en términos de capacidad institucional se derivaba de la implementación de estos programas, se consultó a los responsables técnicos en cada uno de los ayuntamientos sobre: capacidad de gestión e implementación de los diferentes aspectos del programa; la capacidad de gestión de alianzas y, finalmente; la capacidad para aplicar el enfoque integrado. Para todos ellos se consultaba sobre la importancia adoptada en el marco del programa en una escala de valoración de 0 a 5 , donde 0 es la mínima valoración y 5 la máxima, y con la posibilidad de facilitar información suplementaria allí donde el técnico lo estimara conveniente.

\subsection{Capacidad de gestión: Implementación del programa}

Respecto a la capacidad de implementación del programa, se consultó a los técnicos implicados en los programas URBANA 2007-2013 sobre aspectos relacionados con elementos como la organización interna, 
GAPP. Nueva Época - N. ${ }^{\circ}$ 20, noviembre 2018 - ISSN: 1989-8991 - DOI: 10.24965/gapp.v0i20.10487 - [Págs. 124-142] Número monográfico - Gobernanza y políticas de desarrollo urbano: teoría y práctica

La influencia de la iniciativa URBANA $2007-2013$ en el desarrollo de la capacidad institucional de la administración municipal Valle Casado Maestre / María Angeles Huete García / Rafael Merinero Rodríguez / Moneyba González Medina

requerimientos técnicos, distribución de funciones o diversos mecanismos de innovación dentro de la administración local. El análisis de los datos pone de manifiesto que son los requerimientos técnicos, a los que se asocia la adecuada ejecución de los fondos procedentes de la UE, los que constituyen el elemento más importante en relación con la implementación del programa. Son, sin duda alguna estos requerimientos los que marcan la agenda de la gestión de las administraciones locales, tal y como se pone de manifiesto en otros estudios previos realizados respecto a este programa (Busetti et al., 2017). Así, en el trabajo mencionado, ya los técnicos señalaban como elemento característico de estos programas las altas exigencias en su gestión establecidas en la convocatoria para concurrir a los fondos, y que se pone de manifiesto en lo que se conoce como check list del programa o listado de aspectos de la gestión necesarios para poder concurrir y ejecutar adecuadamente los fondos que regulan los programas.

TABLA 5. CAPACIDAD DE GESTIÓN

\begin{tabular}{|c|c|c|c|c|c|}
\hline & $\mathbf{N}$ & Minimum & Maximum & Mean & $\begin{array}{l}\text { Sdt. } \\
\text { Deviation }\end{array}$ \\
\hline $\begin{array}{l}\text { Ha habido una adecuada organización del proceso } \\
\text { de implementación del programa URBANA. }\end{array}$ & 26 & 2 & 5 & 3,62 & ,852 \\
\hline $\begin{array}{l}\text { Se han atendido a los requerimientos técnicos } \\
\text { del programa (checklist). }\end{array}$ & 26 & 3 & 5 & 4,35 & ,745 \\
\hline $\begin{array}{l}\text { Ha habido una adecuada distribución de las funciones } \\
\text { durante el proceso de implementación del programa. }\end{array}$ & 26 & 2 & 5 & 3,88 & ,909 \\
\hline $\begin{array}{l}\text { Se han producido innovaciones en la manera } \\
\text { de gestionar distintos aspectos del gobierno municipal. }\end{array}$ & 26 & 0 & 5 & 2,88 & 1,366 \\
\hline Valid N (listwise). & 26 & & & & \\
\hline
\end{tabular}

Fuente: Elaboración propia.

Ahora bien, la capacidad en términos de gestión se muestra de forma diferenciada en función de experiencia previa. Tal como muestra el análisis de correlación de la Tabla 6, una mayor experiencia se relaciona de forma especialmente significativa con la organización del proceso de implementación. Ello podría estar mostrando que los requerimientos del check list pasan a un segundo plano cuando ya han sido atendidos previamente, adquiriendo importancia otros aspectos como la adecuada implementación del programa.

TABLA 6. RELACIÓN EXPERIENCIA PREVIA EN PROGRAMA EUROPEOS E IMPLEMENTACIÓN DEL PROGRAMA

\begin{tabular}{|c|c|c|c|c|c|}
\hline & & $\begin{array}{l}\text { Ha habido } \\
\text { una adecuada } \\
\text { organización } \\
\text { del proceso de } \\
\text { implementación } \\
\text { del programa } \\
\text { URBANA }\end{array}$ & $\begin{array}{l}\text { Se han } \\
\text { atendido a los } \\
\text { requerimientos } \\
\text { técnicos del } \\
\text { programa } \\
\text { (checklist) }\end{array}$ & $\begin{array}{c}\text { Ha habido una } \\
\text { adecuada distribución } \\
\text { de las funciones } \\
\text { durante el proceso de } \\
\text { implementación del } \\
\text { programa }\end{array}$ & $\begin{array}{l}\text { Se han producido } \\
\text { innovaciones en la } \\
\text { manera de gestionar } \\
\text { distintos aspectos del } \\
\text { gobierno municipal }\end{array}$ \\
\hline \multirow[t]{3}{*}{$\begin{array}{l}\text { Experiencia } \\
\text { previa }\end{array}$} & $\begin{array}{l}\text { Pearson } \\
\text { Correlation }\end{array}$ &, $403^{*}$ & ,230 & ,113 & ,326 \\
\hline & Sig. (2-tailed) & ,041 & ,258 & , 582 & , 104 \\
\hline & $\mathrm{N}$ & 26 & 26 & 26 & 26 \\
\hline
\end{tabular}

Fuente: Elaboración propia.

En otro orden de cosas, el análisis de correlación pone de manifiesto que aquellos modelos organizativos basados en la creación de una oficina exclusiva para la ejecución del programa muestran una mayor importancia de aspectos relacionados con una adecuada gestión de los programas en su conjunto y, de forma 
GAPP. Nueva Época - N. ${ }^{\circ}$ 20, noviembre 2018 - ISSN: 1989-8991 - DOI: 10.24965/gapp.v0i20.10487 - [Págs. 124-142] Número monográfico - Gobernanza y políticas de desarrollo urbano: teoría y práctica

La influencia de la iniciativa URBANA 2007-2013 en el desarrollo de la capacidad institucional de la administración municipal Valle Casado Maestre / María Angeles Huete García / Rafael Merinero Rodríguez / Moneyba González Medina

concreta, aún más respecto a los requerimientos técnicos asociados a la correcta ejecución de los fondos. Resulta llamativa la importancia que se concede a la distribución de funciones en el proceso de implementación cuando el programa se gestiona por varias áreas de la administración municipal.

TABLA 7. RELACIÓN MODELO DE GESTIÓN E IMPLEMENTACIÓN DEL PROGRAMA

\begin{tabular}{|c|c|c|c|c|c|c|}
\hline \multicolumn{2}{|c|}{$\begin{array}{l}\text { Unidad administrativa } \\
\text { gestora del programa } \\
\text { URBANA 2007-2013 }\end{array}$} & $\begin{array}{c}\text { Ha habido } \\
\text { una adecuada } \\
\text { organización } \\
\text { del proceso de } \\
\text { implementación del } \\
\text { programa URBANA }\end{array}$ & $\begin{array}{l}\text { Se han atendido a } \\
\text { los requerimientos } \\
\text { técnicos del } \\
\text { programa } \\
\text { (checklist) }\end{array}$ & $\begin{array}{c}\text { Ha habido } \\
\text { una adecuada } \\
\text { distribución de las } \\
\text { funciones durante } \\
\text { el proceso de } \\
\text { implementación del } \\
\text { programa }\end{array}$ & $\begin{array}{l}\text { Se han producido } \\
\text { innovaciones } \\
\text { en la manera } \\
\text { de gestionar } \\
\text { distintos aspectos } \\
\text { del gobierno } \\
\text { municipal }\end{array}$ & $\begin{array}{c}\text { Media } \\
\text { agregada }\end{array}$ \\
\hline \multirow{3}{*}{$\begin{array}{l}\text { Área/ } \\
\text { delegación } \\
\text { del } \\
\text { Ayuntamiento }\end{array}$} & Mean & 3,50 & 4,30 & 3,70 & 2,90 & 3,60 \\
\hline & $\mathrm{N}$ & 10 & 10 & 10 & 10 & \\
\hline & Std. Deviation & ,850 & ,823 & ,949 & 1,197 & \\
\hline \multirow{3}{*}{$\begin{array}{l}\text { Varias áreas/ } \\
\text { delegaciones } \\
\text { del } \\
\text { Ayuntamiento }\end{array}$} & Mean & 3,75 & 4,13 & 4,13 & 2,50 & 3,62 \\
\hline & $\mathrm{N}$ & 8 & 8 & 8 & 8 & \\
\hline & Std. Deviation & 1,035 & ,835 & ,835 & 1,927 & \\
\hline \multirow{3}{*}{$\begin{array}{l}\text { Área/oficina } \\
\text { creada para } \\
\text { llevar a cabo la } \\
\text { implementación } \\
\text { del programa }\end{array}$} & Mean & 3,75 & 4,67 & 3,92 & 3,25 & 3,89 \\
\hline & $\mathrm{N}$ & 12 & 12 & 12 & 12 & \\
\hline & Std. Deviation &, 754 & ,492 & ,900 &, 965 & \\
\hline
\end{tabular}

Fuente: Elaboración propia.

\subsection{Capacidad para la gestión de las alianzas}

Junto con la gestión, el cuestionario consultaba sobre el establecimiento de relaciones de colaboración con otros actores, ya sea dentro de la administración o con otros actores de la sociedad local. Así, tal y como se observa en la Tabla 7, el mayor efecto se produce respecto al establecimiento de relaciones de colaboración en el interior de la administración local, es decir, que la colaboración entre las distintas áreas del ayuntamiento se potencia en mayor medida que la colaboración con actores de la sociedad local (en segundo lugar) y con otras administraciones (en tercer lugar).

Este aspecto queda también reflejado en otros trabajos realizados en torno a este asunto (Huete et al. 2016) en los que se señala que el carácter integrado de los programas tiene como consecuencia directa la necesidad de establecer alianzas entre las áreas de la administración con capacidad de decisión sobre las áreas de política pública incluidas en el diseño de la iniciativa.

TABLA 8. GOBERNANZA

\begin{tabular}{|c|c|c|c|c|c|}
\hline & $\mathbf{N}$ & Minimum & Maximum & Mean & Sdt. Deviation \\
\hline Entre las distintas áreas del Ayuntamiento. & 26 & 2 & 5 & 4,19 & ,849 \\
\hline $\begin{array}{l}\text { Con otras administraciones (ayuntamientos, } \\
\text { gobierno regional, central, etc.). }\end{array}$ & 26 & 0 & 5 & 3,08 & 1,598 \\
\hline $\begin{array}{l}\text { Con los actores de la sociedad (asociaciones } \\
\text { sociales, deportivas, vecinales, empresariales, de } \\
\text { barrios, empresas, cooperativas, ciudadanía no } \\
\text { organizada, etc.). }\end{array}$ & 26 & 2 & 5 & 3,88 & 1,071 \\
\hline Valid N (listwise). & 26 & & & & \\
\hline
\end{tabular}

Fuente: Elaboración propia. 
GAPP. Nueva Época - N. ${ }^{\circ}$ 20, noviembre 2018 - ISSN: 1989-8991 - DOI: 10.24965/gapp.v0i20.10487 - [Págs. 124-142] Número monográfico - Gobernanza y políticas de desarrollo urbano: teoría y práctica

La influencia de la iniciativa URBANA 2007-2013 en el desarrollo de la capacidad institucional de la administración municipal Valle Casado Maestre / María Angeles Huete García / Rafael Merinero Rodríguez / Moneyba González Medina

Junto a ello, el análisis de correlación entre la capacidad para establecer alianzas con otros actores y la experiencia previa muestra que la importancia del enfoque colaborativo se modifica a medida que se acumula experiencia, evidenciando que esta importancia se produce en mayor medida en las relaciones de colaboración con la sociedad local, si bien los resultados no son significativos.

TABLA 9. RELACIÓN ENTRE EXPERIENCIA EN PROGRAMAS EUROPEOS Y GOBERNANZA

\begin{tabular}{l|l|c|c|c}
\hline & & \multicolumn{1}{c}{$\begin{array}{c}\text { Entre las } \\
\text { distintas } \\
\text { áreas del } \\
\text { Ayuntamiento }\end{array}$} & $\begin{array}{c}\text { Con otras } \\
\text { administraciones } \\
\text { (ayuntamientos, gobierno } \\
\text { regional, central, etc.) }\end{array}$ & $\begin{array}{c}\text { Con los actores de la sociedad } \\
\text { (asociaciones sociales, deportivas, } \\
\text { vecinales, empresariales, de barrios, } \\
\text { empresas, cooperativas, ciudadanía no } \\
\text { organizada, etc.) }\end{array}$ \\
\hline \multirow{2}{*}{$\begin{array}{l}\text { Experiencia } \\
\text { previa }\end{array}$} & $\begin{array}{l}\text { Pearson } \\
\text { Correlation }\end{array}$ &, 121 &, 043 &, 288 \\
\cline { 2 - 5 } & Sig. (2-tailed) &, 556 &, 835 &, 153 \\
\cline { 2 - 5 } & $\mathrm{N}$ & 26 & 26 & 26 \\
\hline
\end{tabular}

Fuente: Elaboración propia.

Respecto a la relación entre los modelos de gestión y el establecimiento de relaciones de colaboración, de forma agregada es el modelo de gestión basado en un área o delegación de la administración local la que permite un mayor desarrollo de la gobernanza en su conjunto, bien porque se le dota de mayor importancia o bien porque suponga en este modelo de gestión en el que mayor esfuerzo se ha tenido que hacer para lograr establecer relaciones de colaboración con otros actores.

TABLA 10. RELACIÓN ENTRE MODELO DE GESTIÓN Y GOBERNANZA

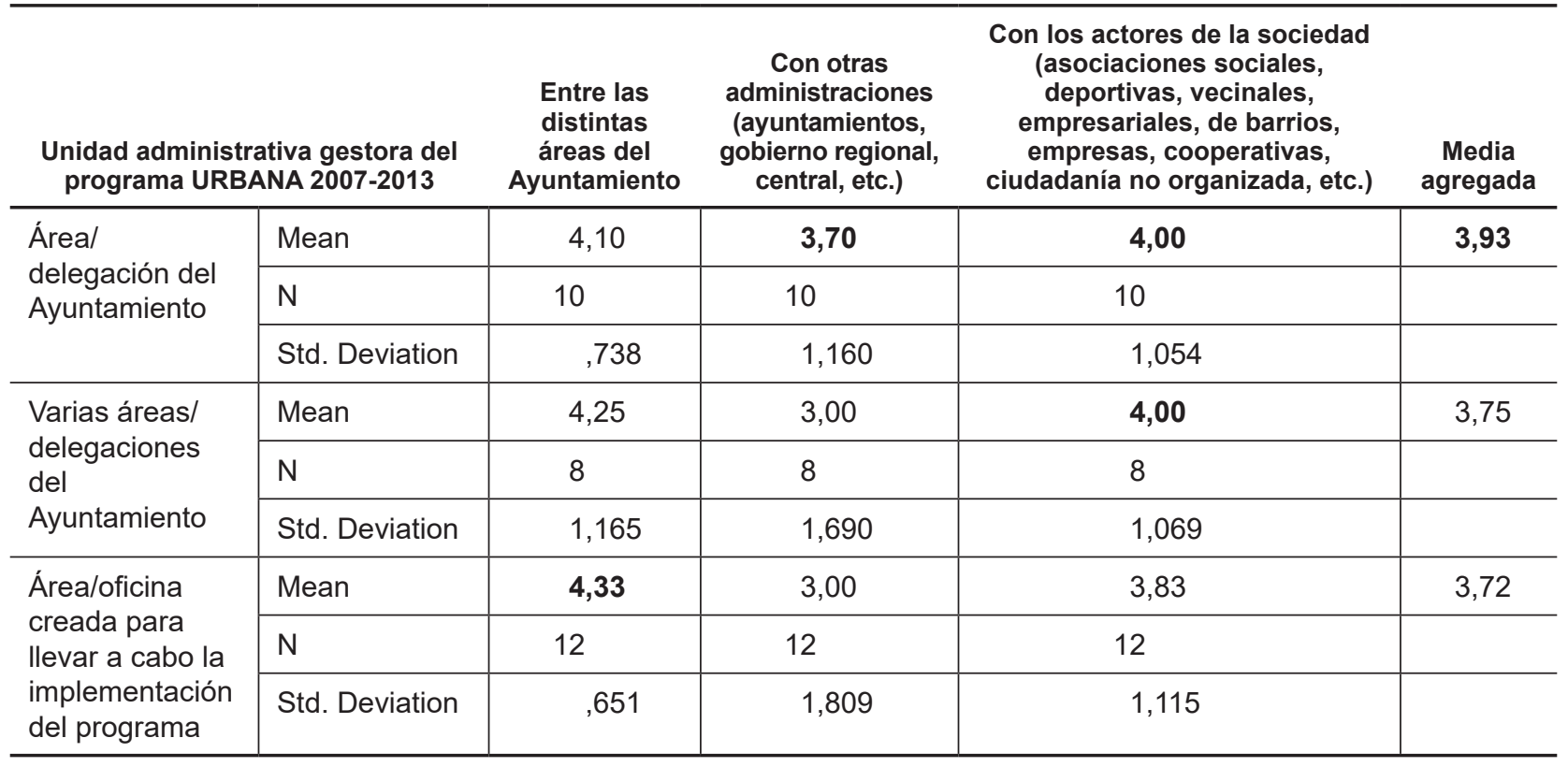

Fuente: Elaboración propia.

\subsection{Capacidad para aplicar el enfoque integrado}

Finalmente, la medición de la capacidad institucional pasaba por analizar la medida en que la administración asume un enfoque integrado, tanto en el diseño como en el diagnóstico de los progra- 
GAPP. Nueva Época - N. ${ }^{\circ}$ 20, noviembre 2018 - ISSN: 1989-8991 - DOI: 10.24965/gapp.v0i20.10487 - [Págs. 124-142] Número monográfico - Gobernanza y políticas de desarrollo urbano: teoría y práctica

La influencia de la iniciativa URBANA 2007-2013 en el desarrollo de la capacidad institucional de la administración municipal Valle Casado Maestre / María Angeles Huete García / Rafael Merinero Rodríguez / Moneyba González Medina

mas $^{6}$. Así, los análisis de ambas cuestiones muestran una importancia muy alta de estos aspectos; constituyendo sin duda alguna el principal aporte a los programas respecto al modelo de desarrollo urbano integrado.

TABLA 11. INTEGRALIDAD

\begin{tabular}{l|c|c|c|c|c}
\hline & \multicolumn{1}{c}{ N } & Minimum & Maximum & Mean & Sdt. Deviation \\
\hline Visión integrada en el DIAGNÓSTICO & 26 & 3 & 5 & $\mathbf{4 , 5 4}$ &, 582 \\
\hline Visión integrada en el DISEÑO & 25 & 3 & 5 & $\mathbf{4 , 3 6}$ &, 700 \\
\hline Valid N (listwise) & 25 & & & & \\
\hline
\end{tabular}

Fuente: Elaboración propia.

Respecto a la relación entre la experiencia previa y la integralidad de las actuaciones, la Tabla 12 pone de manifiesto que existe una relación positiva entre la experiencia previa y la integralidad, más en el diagnóstico que en el diseño, aunque en ambos casos no es significativa.

TABLA 12. RELACIÓN EXPERIENCIA EN PROGRAMAS EUROPEOS E INTEGRALIDAD

\begin{tabular}{l|l|c|r}
\hline & Visión integrada en el DIAGNÓSTICO & Visión integrada en el DISEÑO & Media agregada \\
\hline Experiencia previa & Pearson Correlation &, 118 &, 033 \\
\hline & Sig. (2-tailed) &, 566 &, 877 \\
\hline & N & 26 & 25 \\
\hline
\end{tabular}

Fuente: Elaboración propia.

Por su parte, si se relaciona el modelo de gestión y la integralidad de las actuaciones, se observa una mayor integralidad en los modelos organizativos que han centrado las actuaciones en una sola área municipal, y en segundo lugar en oficinas creadas al efecto.

Ello podría deberse, al igual que en el caso de la gobernanza, a que aquellas iniciativas ubicadas en una sola área municipal han necesitado un mayor esfuerzo por asumir un enfoque integrado, dada la necesidad de incluir tanto en el diagnóstico como en el diseño diversas áreas de política pública, aspecto poco común en modelos de gestión tradicionales en la administración local.

TABLA 13. RELACIÓN MODELO ORGANIZATIVA E INTEGRALIDAD

\begin{tabular}{l|l|c|c|c}
\hline \multicolumn{1}{c}{$\begin{array}{c}\text { Unidad administrativa gestora } \\
\text { del programa URBANA 2007-2013 }\end{array}$} & \multicolumn{2}{c}{$\begin{array}{c}\text { Visión integrada en } \\
\text { el DIAGNÓSTICO }\end{array}$} & $\begin{array}{c}\text { Visión integrada } \\
\text { en el DISEÑO }\end{array}$ & Media agregada \\
\hline \multirow{2}{*}{$\begin{array}{c}\text { Área/delegación del } \\
\text { Ayuntamiento }\end{array}$} & Mean & $\mathbf{4 , 8 0}$ & 4,44 & $\mathbf{4 , 6 2}$ \\
\cline { 2 - 5 } & $\mathrm{N}$ & 10 & 9 & \\
\cline { 2 - 5 } & Std. Deviation &, 422 &, 726 & \\
\hline
\end{tabular}

6 Señale en qué medida está de acuerdo con las siguientes afirmaciones sobre aspectos relacionados con el DISEÑO del programa. Ítems de respuesta: En general, el DIAGNÓSTICO del programa se realizó teniendo en cuenta las diferentes dimensiones de la realidad de la zona objeto de actuación (física, económica, social, ambiental, cultural, etc). En general, el DISEÑO de las actuaciones del programa se realizó teniendo en cuenta las diferentes dimensiones de la realidad de la zona objeto de actuación (física, económica, social, ambiental, cultural, etc.). 
GAPP. Nueva Época - N. ${ }^{\circ}$ 20, noviembre 2018 - ISSN: 1989-8991 - DOI: 10.24965/gapp.v0i20.10487 - [Págs. 124-142] Número monográfico - Gobernanza y políticas de desarrollo urbano: teoría y práctica

La influencia de la iniciativa URBANA 2007-2013 en el desarrollo de la capacidad institucional de la administración municipal Valle Casado Maestre / María Angeles Huete García / Rafael Merinero Rodríguez / Moneyba González Medina

\begin{tabular}{|c|c|c|c|c|}
\hline \multicolumn{2}{|c|}{$\begin{array}{l}\text { Unidad administrativa gestora } \\
\text { del programa URBANA 2007-2013 }\end{array}$} & \multirow{2}{*}{$\begin{array}{c}\text { Visión integrada en } \\
\text { el DIAGNÓSTICO }\end{array}$} & \multirow{2}{*}{$\begin{array}{c}\begin{array}{c}\text { Visión integrada } \\
\text { en el DISEÑO }\end{array} \\
4,25\end{array}$} & \multirow{2}{*}{$\frac{\text { Media agregada }}{4,31}$} \\
\hline Varias áreas/ & Mean & & & \\
\hline Ayuntamiento & $\mathrm{N}$ & 8 & 8 & \\
\hline & Std. Deviation &, 518 & ,707 & \\
\hline \multirow{3}{*}{$\begin{array}{l}\text { Área/oficina creada } \\
\text { para llevar a cabo la } \\
\text { implementación del } \\
\text { programa }\end{array}$} & Mean & 4,50 & 4,50 & 4,50 \\
\hline & $\mathrm{N}$ & 12 & 12 & \\
\hline & Std. Deviation & 674 &, 674 & \\
\hline
\end{tabular}

Fuente: Elaboración propia.

En el marco de este trabajo, al objeto de conocer no solamente la naturaleza del impacto, sino el alcance del mismo, se consultaba sobre la medida en que las mejoras se producían en el área u oficina directamente implicada en la gestión de la iniciativa, en el conjunto de la administración local, o bien en otros programas urbanos no financiados con fondos europeos $y$, por tanto, no supeditados a los requerimientos marcados en la convocatoria ${ }^{7}$.

\section{TABLA 14. PERCEPCIÓN DE LOS EFECTOS DEL PROGRAMA: ÁmBITOS DE ANÁLISIS}

\begin{tabular}{|c|c|c|c|}
\hline \multirow[b]{2}{*}{$\begin{array}{l}\text { Percepción sobre capacidad institucional } \\
\text { adquirida a través del programa }\end{array}$} & \multicolumn{3}{|c|}{ Efectos derivados del programa en... } \\
\hline & $\begin{array}{c}\text { Área/áreas que } \\
\text { implementa el } \\
\text { programa }\end{array}$ & $\begin{array}{c}\text { Conjunto } \\
\text { administración } \\
\text { local }\end{array}$ & $\begin{array}{c}\text { Programas } \\
\text { urbanos no } \\
\text { europeos }\end{array}$ \\
\hline $\begin{array}{l}\text { La motivación y capacitación del personal } \\
\text { municipal. }\end{array}$ & 3,38 & 2,65 & 3,15 \\
\hline $\begin{array}{l}\text { El modelo de gestión de la política (aspectos } \\
\text { relacionados con el cheklist). }\end{array}$ & 3,46 & 3,08 & 3,62 \\
\hline $\begin{array}{l}\text { Trabajo colaborativo entre áreas } \\
\text { de la administración local. }\end{array}$ & 3,85 & 3,69 & 4,08 \\
\hline $\begin{array}{l}\text { Trabajo colaborativo con otras } \\
\text { administraciones públicas. }\end{array}$ & 3,12 & 2,88 & 3,42 \\
\hline Trabajo colaborativo con la sociedad local. & 4,12 & 3,54 & 4,19 \\
\hline $\begin{array}{l}\text { La forma en que se diagnostican los } \\
\text { problemas en las áreas urbanas. }\end{array}$ & 4,00 & 3,42 & 4,15 \\
\hline $\begin{array}{l}\text { La forma en que se diseñan las políticas } \\
\text { para las áreas urbanas. }\end{array}$ & 3,77 & 3,56 & 3,73 \\
\hline $\begin{array}{l}\text { La forma en que se implementan las políticas } \\
\text { para las áreas urbanas. }\end{array}$ & 3,77 & 3,46 & 3,81 \\
\hline
\end{tabular}

7 La formulación de las preguntas se hacía de la siguiente forma:

P8. En una escala de valoración de 0 a 5 , donde 0 es la mínima valoración y 5 la máxima, señale en qué medida considera que la implementación del programa URBANA ha supuesto una mejora sustancial de la gestión del ÁREA MUNICIPAL en la que usted desempaña su trabajo.

P9. En una escala de valoración de 0 a 5 , donde 0 es la mínima valoración y 5 la máxima, señale en qué medida considera que la implementación del programa URBANA ha supuesto una mejora sustancial de la gestión en el CONJUNTO DE SU ADMINISTRACIÓN LOCAL.

P10. En una escala de valoración de 0 a 5 , donde 0 es la mínima valoración y 5 la máxima, señale en qué medida considera que la experiencia acumulada a través de la implementación del programa URBANA será de utilidad para la implementación en el futuro de otras ACTUACIONES, NO FINANCIADAS con fondos europeos. 
GAPP. Nueva Época - N. ${ }^{\circ}$ 20, noviembre 2018 - ISSN: 1989-8991 - DOI: 10.24965/gapp.v0i20.10487 - [Págs. 124-142] Número monográfico - Gobernanza y políticas de desarrollo urbano: teoría y práctica

La influencia de la iniciativa URBANA 2007-2013 en el desarrollo de la capacidad institucional de la administración municipal Valle Casado Maestre / María Angeles Huete García / Rafael Merinero Rodríguez / Moneyba González Medina

\begin{tabular}{l|c|c|c}
\hline \multirow{2}{*}{$\begin{array}{c}\text { Percepción sobre capacidad institucional } \\
\text { adquirida a través del programa }\end{array}$} & $\begin{array}{c}\text { Área/áreas que } \\
\text { implementa el } \\
\text { programa }\end{array}$ & $\begin{array}{c}\text { Conjunto } \\
\text { administración } \\
\text { local }\end{array}$ & $\begin{array}{c}\text { Programas } \\
\text { urbanos no } \\
\text { europeos }\end{array}$ \\
\cline { 2 - 4 } $\begin{array}{l}\text { La forma en que se evalúan las políticas } \\
\text { para las áreas urbanas. }\end{array}$ & 3,65 & 3,23 & 3,60 \\
\hline $\begin{array}{l}\text { Media total_Índice de Capacidad } \\
\text { Institucional. }\end{array}$ & 3,68 & 3,27 & 3,75 \\
\hline
\end{tabular}

Fuente: Elaboración propia.

Tal y como se muestra en el análisis descriptivo, la percepción de los técnicos implicados en la implementación de las iniciativas URBANA es que los impactos se han producido en mayor medida en aquellos programas urbanos que se gestionen en el futuro y no implementados con fondos europeos ( 3,75 de media). Ello es destacable, pues muestra un efecto de difusión de esta metodología en ámbitos no asociados a una obligatoriedad de la aplicación del enfoque urbano para la obtención de los fondos y en definitiva una capacidad institucional real y no tanto una adaptación temporal de las administraciones, forzada por los requisitos asociados a la obtención de los fondos con los que se financian los programas. También sugiere que este tipo de enfoques integrados resultan más adecuados para abordar problemas urbanos, caracterizados por su naturaleza compleja.

GRÁFICO 1. IMPACTO EN TÉRMINOS DE CAPACIDAD INSTITUCIONAL: ÁMBITOS/NIVELES

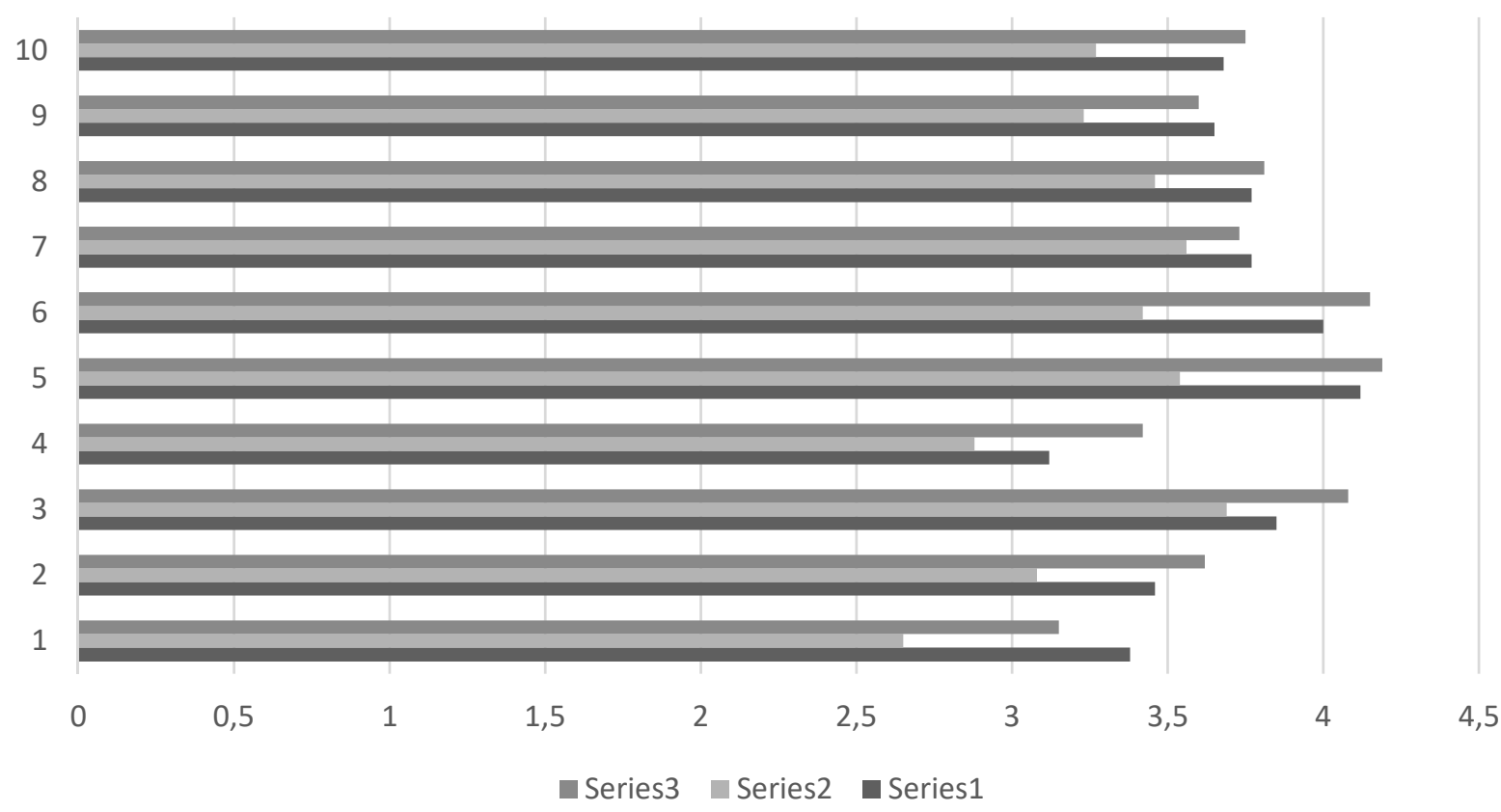

Fuente: Elaboración propia: Serie 1: Área/áreas que implementan el programa; Serie 2: Conjunto de la administración local; Serie 3: Programas no europeos.

Junto a ello, resulta llamativo que se señale como principal mejora el trabajo colaborativo con la sociedad local que, como se señalaba en el análisis de la primera dimensión (procedimientos formales de la convocatoria), no son aquellos que constituyen un elemento indispensable para la accesibilidad a los fondos por parte de las ciudades que concurren a la convocatoria, sino un aspecto a valorar en la evaluación de los proyectos. 
GAPP. Nueva Época - N. 20, noviembre 2018 - ISSN: 1989-8991 - DOI: 10.24965/gapp.v0i20.10487 - [Págs. 124-142] Número monográfico - Gobernanza y políticas de desarrollo urbano: teoría y práctica

La influencia de la iniciativa URBANA $2007-2013$ en el desarrollo de la capacidad institucional de la administración municipal Valle Casado Maestre / María Angeles Huete García / Rafael Merinero Rodríguez / Moneyba González Medina

En este sentido, el discurso desde el nivel de gobierno central es coherente con las percepciones de los técnicos locales encuestados. Así, uno de los entrevistados (ES1N) manifestaba su esperanza en que la forma de trabajar que se está produciendo en los ayuntamientos permanezca más allá de la finalización de las ayudas. Dicho impacto se percibe de forma especial en relación con la colaboración con la sociedad local. Desde su punto de vista, «existe tal implicación de la sociedad local en estos programas, que la misma no permitiría que el ayuntamiento volviera a la forma de trabajar anterior». De la misma forma ES3N señalaba que «en el periodo presupuestario anterior, cuando se terminaron los fondos que tuvieron buenos resultados, algunos ayuntamientos siguieron financiando las actuaciones con su presupuesto propio». En definitiva, estos fondos están siendo considerados como una oportunidad para iniciar caminos nuevos, que los ayuntamientos podrán seguir desarrollando con presupuesto propio.

Por otra parte, se ha señalado como un impacto significativo tanto en el área que directamente ha gestionado el programa, como en futuros programas urbanos el enfoque integrado especialmente en el diagnóstico del programa.

En esta línea, los técnicos del Ministerio de Hacienda manifestaban un fuerte convencimiento en que estos programas han generado un cierto modo de pensar que se pone de manifiesto en la planificación de las políticas. Desde su perspectiva, estos programas suponen una «palanca para hacer cosas». «La gente quiere hacer las cosas bien y esto es un marco facilitador. Tanto los políticos, como los técnicos».

\section{CONCLUSIONES}

Este trabajo ha tratado de aproximarse a los efectos que en términos de capacidad institucional se derivan de la implementación de programas europeos en las administraciones locales. En concreto, se ha tomado como unidad de observación el programa URBANA, impulsado por España en el marco de la programación del FEDER para el periodo 2007-2013.

Como primer hallazgo, puede afirmarse que las dimensiones de la capacidad institucional son válidas para comprender los procesos de adaptación de las administraciones locales al modelo de desarrollo urbano propuesto en el ámbito europeo, especialmente a partir de la Carta de Leipzig (2007) y en el contexto del proceso de reflexión «Cities of Tomorrow», iniciado en 2009. En consecuencia, se constanta que la política urbana europea tiene un impacto en la transformación de la capacidad institucional de los municipios que participan en ella a través de proyectos y/o redes. Este trabajo ha tratado de analizar cómo se produce ese impacto, cuál es su naturaleza y en qué medida se implanta en la administración local.

En relación a las dimensiones de la capacidad institucional, las conclusiones se obtienen a partir de una combinación de tres elementos: implementación del programa (organización del trabajo, requerimientos técnicos, etc.); gobernanza o relaciones de cooperación; y enfoque integrado en el diagnóstico y diseño de las actuaciones. Estas dimensiones se combinan con información relativa al modelo de gestión del programa en el seno de la administración local, y a la experiencia previa del municipio en la gestión de otros programas europeos de carácter urbano implementados con anterioridad.

En cuanto a la manera en la que se implementa el programa en el seno de los ayuntamientos, se puede concluir de manera general que, cuando no existe una experiencia previa, la fuente de conocimiento que suponen los requerimientos técnicos del programa es fundamental para un adecuado desarrollo de los mismos. A medida que el ayuntamiento tiene experiencia previa en el desarrollo de programas, la organización del proceso y la distribución de funciones en el seno de la administración local adquiere una mayor importancia. Por lo tanto, los procesos de aprendizaje derivados de la experiencia previa permiten la introducción de innovaciones en la gestión con resultados más satisfactorios que en los casos donde no existe una experiencia previa.

De esta manera, el desarrollo de la capacidad institucional que depende de las innovaciones introducidas en la gestión de la administración local, como resultado de la implementación de programas europeos de carácter urbano, es mayor en los casos en los que existe una experiencia previa, si bien el desarrollo de la capacidad institucional se produce en cualquier caso como resultado del cumplimiento de los requerimientos técnicos del programa del URBANA, que son coincidentes con los de otros programas europeos previos y posteriores.

Si se atiende al análisis de la implementación del programa en función de la estructura de gestión de la administración local, se pone en evidencia que en aquellos casos en los que se ha creado una oficina o unidad ex profeso para la implementación del programa europeo se ha prestado más atención a los aspectos 
GAPP. Nueva Época - N. 20, noviembre 2018 - ISSN: 1989-8991 - DOI: 10.24965/gapp.v0i20.10487 - [Págs. 124-142] Número monográfico - Gobernanza y políticas de desarrollo urbano: teoría y práctica

La influencia de la iniciativa URBANA $2007-2013$ en el desarrollo de la capacidad institucional de la administración municipal Valle Casado Maestre / María Angeles Huete García / Rafael Merinero Rodríguez / Moneyba González Medina

relacionados con la implementación: organización del proceso, distribución de tareas, atención a los requerimientos técnicos, etc. Esto se traduce en que la creación de una estructura de gestión para la implementación de programas europeos de carácter urbano permite una introducción más sólida de innovaciones en la gestión de la administración local y, por lo tanto, en el desarrollo de la capacidad institucional de las mismas. Habrá que ver si este elemento favorece asimismo la durabilidad de los cambios introducidos y el impacto en el conjunto de la administración.

En relación con la capacidad para asumir un enfoque colaborativo, parece que el mayor índice de cooperación durante la implementación del programa se da entre las distintas áreas de la administración local, por encima de las relaciones con la sociedad local y de las relaciones con otros niveles de administración, provincial, regional o estatal. Esto puede deberse al esfuerzo de adaptación al carácter integral de los procesos y de las políticas que se desarrollan en el marco de los programas urbanos europeos, que han de tener en cuenta los distintos sectores involucrados: medioambiental, social, económico, etc. Se observa, sin embargo, que a medida que las administraciones locales van adquiriendo experiencia en la implementación de estos programas, se van entretejiendo cada vez más relaciones con la sociedad local.

Puesta en relación la dimensión de la gobernanza con la estructura de gestión, el impacto del desarrollo de la capacidad institucional en el conjunto de la administración es mayor cuando la gestión se ubica en un área de la misma.

En relación con el enfoque integrado en el diagnóstico y diseño de las actuaciones, se concluye de manera nítida una relación clara entre la implementación del programa URBANA y la adquisición de esta dimensión propia de la capacidad institucional. Es decir, el enfoque integrado se señala tras este estudio como uno de los efectos más destacables tras su implementación.

A medida que la administración adquiere experiencia, se asume con mejores resultados este cambio. Puesto en relación con la estructura de gestión, ocurre lo mismo que en el ámbito de la gobernanza, donde se asumen mejor los cambios cuando se trata de una gestión llevada a cabo en un área de la propia administración.

En definitiva, podría afirmarse que los procesos de aprendizaje derivados de la práctica de sucesivos programas permiten una permeabilidad mayor de las innovaciones producidas como efecto de la implementación de los programas y, por lo tanto, una permanencia de los efectos que va calando en el conjunto de la administración local.

Finalmente, a tenor de las percepciones de los técnicos entrevistados, se puede decir que existe un cierto aprendizaje derivado de la implementación de estos programas y que además puede suponerse que no permanece solamente en las unidades administrativas directamente vinculadas a la gestión de los mismos, sino que con ello se produciría un efecto de difusión de estos modelos de implementación en otras áreas de la administración, así como en otros ámbitos de política pública, produciéndose por tanto un crecimiento real en términos de capacidad institucional y no solamente una mera adaptación de las administraciones a los requerimientos establecidos por aquellos que regulan los fondos.

\section{REFERENCIAS BIBLIOGRÁFICAS}

ATKINSON, R. y ROSSIGNOLO, C. (2009): "An «Explicit» EU Urban Policy After a «Learning» Phase? International Conference". City Futures '09, Madrid, 4-6 junio.

BÖHME, K., ZILLMER, S., TOPTSIDOU, M. y HOLSTEIN, F. (2015): Territorial governance and Cohesion policy, Documento solicitado por e European Parliament's Committee on Regional Development. Directorate-General for Internal Policies.

BUSETTI, GONZÁLEZ, HUETE y MERINERO (2018): "Repensando el diseño de las políticas públicas. Los mecanismos causales de la participación social en el programa de regeneración urbana de Alcalá de Guadaíra (España)”, en Revista Española de Investigaciones Sociológicas (REIS), núm. 164 (Octubre-Diciembre), págs. 77-96.

BUSETTI, S. y PACCHI, C. (2015): "Institutional Capacity for EU Cohesion Policy: Concept, Evidence and Tools that matter", en The Planning Review, vol. 50, núm. 4, págs. 16-28. DOI: https://doi.org/10.1080/02513625.2014.1007657.

DE GREGORIO HURTADO, S. (2010): "El desarrollo de las iniciativas comunitarias URBAN y URBAN II en las periferias degradadas de las ciudades españolas. Una contribución a la práctica de la regeneración urbana en España", en Ciudades, núm. 13, págs. 39-59. DOI: https://doi.org/10.24197/ciudades.13.2010.39-59.

DE GREGORIO HURTADO, S. (2014): "La Iniciativa Comunitaria URBAN como factor de transformación de la práctica de la regeneración urbana: aproximación al caso español", en Ciudad y Territorio, núm. 180, págs. 253-275.

GONZÁLEZ MEDINA, M. (2011): "Elementos de una política urbana europea. Experiencias de gestión del desarrollo urbano en Alemania y España", en Revista Española de Ciencia Política, núm. 27, págs. 45-67. 
GAPP. Nueva Época - N. 20, noviembre 2018 - ISSN: 1989-8991 - DOI: 10.24965/gapp.v0i20.10487 - [Págs. 124-142] Número monográfico - Gobernanza y políticas de desarrollo urbano: teoría y práctica

La influencia de la iniciativa URBANA $2007-2013$ en el desarrollo de la capacidad institucional de la administración municipal Valle Casado Maestre / María Angeles Huete García / Rafael Merinero Rodríguez / Moneyba González Medina

GONZÁLEZ MEDINA, M. (2013): “La europeización urbana a través de la política de cohesión”, en Revista CIDOB d’Afers Internacionals, núm. 104, págs. 133-154.

GONZÁLEZ MEDINA, M. y MERINERO, R.: “¿Evaluar la gobernanza?: análisis de la planificación estratégica urbana como instrumento de gobernanza territorial en Italia y España”. Ponencia presentada en el XI Congreso de la Asociación Española de Ciencia Política y de la Administración, Sevilla, 18-20 de septiembre.

HEALEY, P. (1998): "Building Institutional Capacity through Collaborative Approaches to Urban Planning", en Environment and Planning A: Economy and Space, vol. 30, núm. 9, págs.1531-1546. DOI: https://doi.org/10.1068/ a301531.

HILDERBRAND, M. E., GRINDLE, M. S. (1997): "Building Sustainable Capacity in the Public Sector. What Can Be Done?". Getting Good Government. ed. Harvard University Press. Boston, MA.

HUBER, G. P. (1991): "Organizational Learning: the contributing processes and the literatures". Organization Science, vol. 2, núm. 1, 88-115. https://doi.org/10.1287/orsc.2.1.88.

HUETE GARCÍA, M. A.; MERINERO RODRÍGUEZ, R. y MUÑOZ, R. (2016): "Urban regeneration policy from the Model of Integrated Urban Development in the European Union: an analytical approach based on the study of Spanish cities". Local Government Studies, núm. 42, vol. 2, págs. 267-286. https://doi.org/10.1080/03003930.201 5.1110520.

PARÉS, M., MARTÍ, M., BLANCO, I. (2014): "Geographies of governance: how place matters in urban regeneration policies”. Urban Studies, vol. 51, núm. 15, 2014, págs. 3.250-3.267. https://doi.org/10.1177/0042098013513647.

PINSON, G. (2011): “Urbanismo y gobernanza de las ciudades europeas: gobernar la ciudad por proyecto". Desarrollo Territorial, 10, Universidad de Valencia.

RADAELLI, C. (2003): "The Europeanization of Public Policy", in Featherstone e Radaelli (eds.), The Politics of Europeanization, Oxford, Oxford University Press: 27-56.

REAL DATO, J. (2007): "Mecanismos de cambio en las políticas públicas: propuesta de un marco teórico-conceptual sintético", VIII Congreso Español de Ciencia Política y de la Administración Política para un mundo en cambio, (grupo de trabajo 17) (Análisis y Evaluación de Políticas Públicas).

REPETTO, F. (2003): "Capacidad estatal: requisito necesario para una mejor política social en América Latina". VIII Congreso Internacional del CLAD sobre la Reforma del Estado y de la Administración Pública, Panamá: 28-31.

ROSAS HUERTA, A. (2008): "Una ruta metodológica para evaluar la capacidad institucional”. Política y Cultura, 30, págs. 119-134.

SAVITCH, H. V. (1998): "Global challenge and institutional capacity: or, how we can refit local administration for the next century". Administration \& Society, vol. 30 (3). https://doi.org/10.1177/0095399798303002.

SIKKINK, K. (1993) "Las capacidades y la autonomía del Estado en Brasil y la Argentina. Un enfoque institucionalista". Desarrollo Económico, Buenos Aires (128).

\section{DOCUMENTOS}

COM (2015). Hoja informativa: Mejorar la forma en que los Estados miembros y las regiones de la UE invierten y gestionan los fondos de la política de cohesión de la UE.

COM (2011): Cities of tomorrow. Challenges, visions, ways forward. Bruselas.

COM (2006: 385 final). Comunicación de la Comisión al Consejo y al Parlamento europeo: Política de Cohesión y ciudades: la contribución urbana al crecimiento y el empleo en las regiones.

EUROPEAN UNION, ESF (2011): "Institutional capacity: Public administration and services in European Social Fund 2007-2013”, Bruxelles, EU: https://publications.europa.eu/es/publication-detail/-/publication/87bae5ca-9ef0-480f96fc-657e87cbd80d/language-en.

EUROPEAN UNION (2014): "Draft Thematic Guidance Fiche for Desk Officers. Institutional Capacity-building" (THEMATIC OBJECTIVE 11) VERSION 2 - 22-01-2014 RELEVANT PROVISIONS IN THE LEGISLATION, disponible en: http://ec.europa.eu/regional_policy/sources/docgener/informat/2014/guidance_fiche_thematic objective_11_en.pdf.

REUNIÓN INFORORAL DE MINISTROS RESPONSABLES DE DESARROLLO URBANO (2007); "Carta de Leipzig sobre ciudades europeas sostenibles", disponible en: https://www.fomento.gob.es/NR/rdonlyres/91B5958A-585C4E92-8B1F-C06F5CBC4C4B/111500/LeipzigCharte_Es_cle139ba4.pdf. 